\title{
High-performance Energy Storage System Using Low-cost Sensors for a Photovoltaic and Battery Hybrid System
}

\author{
Pi-Yun Chen, Kuei-Hsiang Chao, ${ }^{*}$ and Yu-Sheng Tsai \\ Department of Electrical Engineering, National Chin-Yi University of Technology, \\ No. 57, Sec. 2, Zhongshan Rd. Taiping Dist. Taichung 41170, Taiwan (ROC)
}

(Received Novembe 19, 2018; accepted May 7, 2019)

Keywords: battery charger, photovoltaic module array, buck converter, maximum power point tracker, two-stage charging strategy

In this paper, we present a high-speed battery charger, powered by a photovoltaic (PV) module array, for a $\mathrm{LiFePO}_{4}$ battery as a solar energy storage device. With a battery charging strategy, the presented battery charger involves a buck converter as the core equipped with a simple maximum-power-point (MPP) tracker. Considering complexity reduction and easy hardware implementation, a constant-voltage MPP tracking approach is adopted such that the maximum amount of output power can be delivered to the load in response to an arbitrary change in the level of solar radiation. A two-stage charging strategy, with temperature monitoring in a constant current mode followed by a constant voltage mode, is employed in such a way that the battery charge process can be markedly accelerated, while the damage caused by overcharging can be prevented. Finally, the performance of the proposed energy storage system using low-cost voltage, current, and temperature sensors for a PV and battery hybrid system is validated experimentally.

\section{Introduction}

There is a rapid rise in electricity price as a consequence of the upcoming global oil crisis, and the search for and the development of alterative energy sources, particularly green energy sources, become a critical issue. Solar energy has long been seen as a promising candidate energy source to resolve the threat of oil crisis, but a disadvantage is that the generated solar power cannot be well regulated owing to a number of factors, e.g., time-varying solar radiation, climate uncertainty, and so forth. Hence, it is a significant and urgent issue to improve the performance of solar power generators in practical uses. ${ }^{(1)}$

As a reusable electric device, secondary batteries continue to gain worldwide attention owing to global warming and ecofriendly concerns. In an attempt to reduce the amount of $\mathrm{CO}_{2}$ emission, a great number of research institutes and business entities have made continuous effort to search for alternative energy sources, such as solar power, wind power, and fuel cell, or to improve the conversion of secondary batteries. There is no doubt that Li-ion batteries will

*Corresponding author: e-mail: chaokh@ncut.edu.tw https://doi.org/10.18494/SAM.2019.2200 
gradually take the place of lead-acid and Ni-hydrogen batteries in the long term; particularly, $\mathrm{LiFePO}_{4}$ batteries rank first among a wide variety of $\mathrm{Li}$-ion batteries owing to their high capacity and long service time. ${ }^{(2)}$ In addition, $\mathrm{a} \mathrm{LiFePO}_{4}$ battery does not require a high current charger, indicating that it can be charged by a solar-powered battery charger even at low levels of solar radiation. The performance is validated experimentally only using low-cost voltage, current, and temperature sensors.

The output power of a photovoltaic (PV) module is a function of solar radiation, module temperature, and so forth. Owing to efficiency concerns, the maximum power point (MPP) is tracked by a constant-voltage MPP tracking approach herein so as to transfer the maximum amount of power at all events to a $\mathrm{LiFePO}_{4}$ battery through the presented battery charger. A two-stage charging strategy is employed in such a way that the charger works in the constant current mode to speed up the charging of a high-capacity $\mathrm{LiFePO}_{4}$ battery, and then operates in the constant voltage mode so as to keep the battery voltage below the evaporation voltage for safety concern. In this manner, efficiency improvement, charge process acceleration, and an extended battery life are hence achieved.

For the performance testing of this presented two-stage battery charging strategy, high current charge/discharge characteristic curves of a $\mathrm{LiFePO}_{4}$ battery, i.e., plots of the battery voltage, current, and state of charge (SOC) against time, are obtained for the behavioral analysis of batteries.

\section{Solar Cell}

\subsection{Solar cell basics}

A solar cell is a semiconductor device. Over the electrically neutral PN region, electron-hole pairs are generated as a consequence of incident solar energy. Owing to the effect of the electric field across the depletion region, electrons and holes drift across the $\mathrm{P}-\mathrm{N}$ junction toward the $\mathrm{N}$ and $\mathrm{P}$ regions, respectively. Illustrated in Fig. 1 is a mathematic model of a solar cell, where $I_{p h}$ represents the short-circuit current at a given level of solar radiation and $R_{S}$ the contact resistance between the metal electrodes and the semiconductor material.

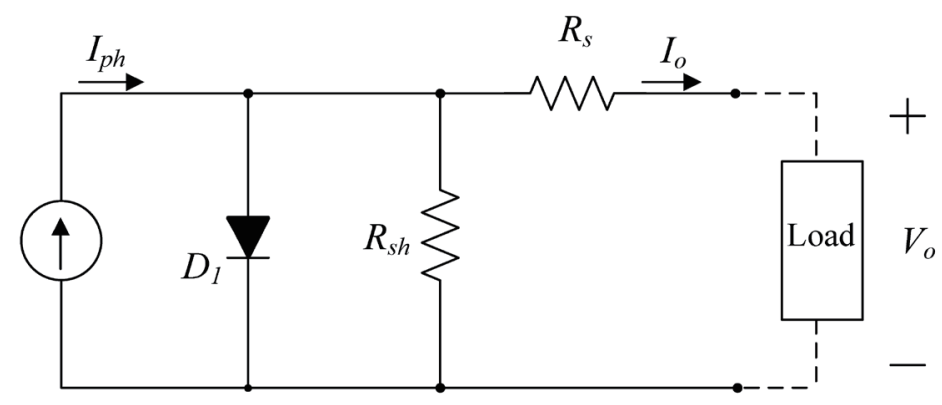

Fig. 1. Circuit model of a PV cell. 
The output current $I_{o}$, provided by a solar cell, is given as

$$
I_{O}=I_{p h}-I_{\text {sat }}\left[\exp \left(\frac{q\left(V_{O}+I_{O} R_{S}\right)}{A K T}\right)-1\right]-\frac{V_{O}+I_{O} R_{S}}{R_{s h}}
$$

where $I_{p h}$ represents the short-circuit current at a given level of solar radiation,

$I_{\text {sat }}=$ reverse saturation current of the diode $D_{1}$,

$q=$ charge carried by a single electron $\left(1.6 \times 10^{-19} \mathrm{C}\right)$,

$V_{o}=$ output voltage of the solar cell,

$A=$ dielectric constant (1-2),

$K=$ Boltzmann's constant $\left(1.3806505 \times 10^{-23} \mathrm{JK}^{-1}\right)$,

$R_{s h}=$ equivalent shunt resistance,

$R_{S}=$ equivalent series resistance, and

$T=$ surface temperature of the solar cell $\left[25^{\circ} \mathrm{C}(298 \mathrm{~K})\right]$.

\subsection{MPP tracking strategies for a PV module array}

The performance of a PV module array and MPPs demonstrate a strong dependence on exterior factors, e.g., solar radiation, temperature, and so forth. In consideration of efficiency optimization, an MPP tracker is employed to deliver the maximum amount of solar power to the load. Up to now, there have been a great number of published studies on this issue, ${ }^{(3,4)}$ among which the constant voltage, power feedback, perturb and observe, incremental conductance methods, and so on are the most commonly seen approaches, and the constant voltage method is demonstrated as the easiest and simplest way to perform a tracking task. The idea is to make a PV module array work at a specific output voltage. Illustrated in Fig. 2 is a oneparameter family of $I-V$ characteristic curves. As revealed, the MPP voltage demonstrates little dependence on the level of solar radiation. In simple terms, the design complexity of an MPP tracker can be reduced considerably, provided that the tracker is operated at the maximum power voltage specified in the datasheet thereof. On account of the high reliability, high

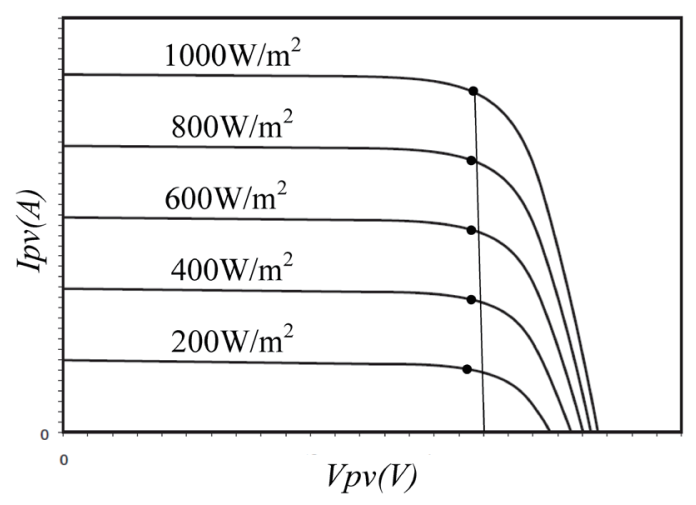

Fig. 2. Family of $I-V$ characteristic curves of a PV module array with the solar radiation level as a parameter. 
stability, and low cost of the constant-voltage MPP tracking approach, this approach is employed herein.

\section{Programmable Interface Controller (PIC) Microcontroller}

PIC series microcontrollers, including 8-, 16-, and 32-bit microcontrollers, are provided by Microchip Technology Inc. ${ }^{(5)}$ As the controller core, a PIC18F8720 microcontroller ${ }^{(6)}$ is employed with the following underlying key features:

(1) a high-performance reduced instruction set computing (RISC) CPU,

(2) linear program memory addressing to $128 \mathrm{kB}$, linear data memory addressing to 3840 bytes, $1 \mathrm{kB}$ of data EEPROM, up to $10 \mathrm{MIP}$ operation, DC - $40 \mathrm{MHz}$ osc./clock input with PLL active loop filter,

(3) a 16-bit external memory interface, address capability of up to $2 \mathrm{MB}$,

(4) a high-current sink/source $(25 \mathrm{~mA} / 25 \mathrm{~mA})$,

(5) four external interrupt pins,

(6) five capture/compare/PWM (CCP) modules,

(7) a programmable 16-level low-voltage detection (LVD) module, and

(8) a 10-bit, up to 16-channel analog-to-digital converter (A/D).

\section{Charge/Discharge Characteristics of a Li-Iron Battery}

\subsection{Li-iron battery survey}

Among a wide range of secondary batteries, lithium-ion, particularly Li-iron, ${ }^{(7)}$ batteries gain wide popularity in practical applications owing to their advantages of high energy density, high discharge voltage, low self-discharge rate, no memory effect, and long battery life. $\mathrm{LiFePO}_{4}$ batteries, also known as $\mathrm{Li}$-iron batteries, were proposed in 1997 by Padhi and coworkers ${ }^{(8-10)}$ with $\mathrm{LiFePO}_{4}$ as a positive electrode material. In contrast to conventional $\mathrm{LiMn}_{2} \mathrm{O}_{4}, \mathrm{LiNiO}_{2}$, and $\mathrm{LiCoO}_{2}$, batteries, a $\mathrm{LiFePO}_{4}$ battery does not contain any precious metals, e.g., $\mathrm{Mn}, \mathrm{Ni}$, and $\mathrm{Co}$; hence, it acquires a cost advantage. In addition, it is a high-safety, high-capacity, and ecofriendly energy storage device.

As opposed to inherently unsafe $\mathrm{LiCoO}_{2}$ batteries, there exists a strong covalent bond between molecules of positive electrode materials in a $\mathrm{LiFePO}_{4}$ battery. For this reason, the risk of explosion and flame is completely removed during the use of $\mathrm{LiFePO}_{4}$ batteries, a clear advantage over other types of batteries. Moreover, $\mathrm{LiFePO}_{4}$ batteries serve as a highperformance energy storage device, since the requirements of high capacity, zero pollution, low self-discharge rate, long service life (the number of discharge and charge cycles), high coulombic efficiency, light weight, and high safety can be fulfilled. Furthermore, it features high-current charge/discharge.

Accordingly, a $48 \mathrm{~V} 10$ Ah EA-480100-C15 $\mathrm{LiFePO}_{4}$ battery is employed as an energy storage device for the presented PV system. The specifications of the Li-iron battery are given in Table 1. 
Table 1

$\mathrm{LiFePO}_{4}$ battery specifications.

\begin{tabular}{lc}
\hline Name & EA-480100-C15 \\
\hline Rated capacity & $10 \mathrm{Ah}$ \\
Rated voltage & $52.8 \mathrm{~V}$ \\
Charging cutoff voltage & $58.4 \mathrm{~V}$ \\
Discharging cutoff voltage & $45.6 \mathrm{~V}$ \\
Maximum charge current & $10 \mathrm{~A}$ \\
Temperature range of charging & $0-60^{\circ} \mathrm{C}$ \\
Temperature range of discharging & $-20-70{ }^{\circ} \mathrm{C}$ \\
\hline
\end{tabular}

\subsection{PIC microcontroller charging strategies for $\mathrm{Li}$-iron batteries}

PIC series microcontrollers, including 8-, 16-, and 32-bit microcontrollers, are provided by Microchip Technology Inc. ${ }^{(5)}$ As the controller core, a PIC18F8720 microcontroller ${ }^{(6)}$ is employed with the following underlying key features: The way to charge a battery is found to significantly affect the service life of the battery. Hence, a recommended battery charge strategy can be found in an official guide provided by each battery manufacturer. Yet, it takes a relatively long time to charge a battery, namely, a slow paced charge strategy due to safety concerns. Nonetheless, high-performance charge strategies become a key issue in the development of battery chargers in an attempt to meet the cost reduction requirement in today's highly competitive market. Batteries are characterized in official user guides in terms of cutoff voltage, charge voltage, maximum charge current, maximum continuous discharge current, and so forth. Hence, a high-performance battery charger must be developed in compliance with the specifications.

As stated in Ref. 11, there are up to five ways to charge a Li-iron battery as a rule. The battery charging strategy employed herein consists of two stages, namely, the constant current mode followed by the constant voltage mode; such a strategy benefits from both charging modes. In this fashion, the charging time of a battery can be reduced considerably when operated in the constant current mode, while the service life of a battery can be well maintained when in the constant voltage mode. During the first stage of charging, the battery charger works in the constant current mode for efficiency concern. When the battery output voltage approaches a specified threshold, the charger switches to the constant voltage mode to protect the battery from overcharging. Charging continues until the voltage threshold is reached.

Presented in Fig. 3 is an illustration of a two-stage battery charging approach. The first stage is the so-called bulk charging step, since high-speed battery charging is performed by a charger operating in the constant current mode. The process proceeds until a voltage threshold is reached. At this point in time, the battery is not fully charged, not in a $100 \%$ SOC. Hence, the charging process moves into the second stage, that is, the constant voltage mode. Over the second stage, the charge current falls steeply, but the battery voltage rises smoothly, with time, until another voltage threshold (a 100\% SOC) is reached. 


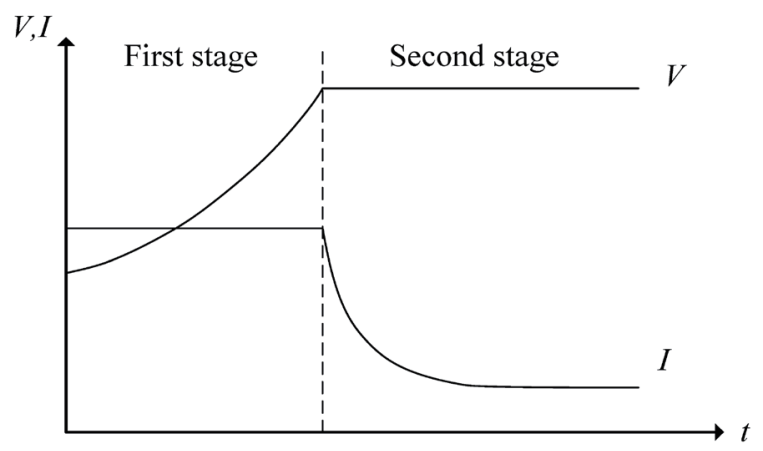

Fig. 3. Schematic of a two-stage battery charging strategy.

\section{Li-Iron Batteries as Solar Energy Storage Devices}

\subsection{Step-down DC-DC converter}

In terms of circuit configuration, nonisolated DC-DC converters can be categorized into, for example, buck, boost, buck-boost, Ćuk, SEPIC, and Zeta converters. ${ }^{(12)}$ A buck converter is employed herein owing to the advantage of easy hardware implementation. Sketched in Fig. 4 is the framework of a buck converter, also known as a voltage step-down converter, since the converter's output voltage is kept below the input at all events.

According to the volt-second balance, the input and output voltages are related, ${ }^{(12)}$

$$
V_{o}=V_{s} D
$$

\subsection{Battery charger framework}

Demonstrated in Fig. 5 is a schematic diagram of the presented Li-iron battery charger mainly based on a buck converter with an inductor $L_{1}$, a capacitor $C_{1}$, a high-speed switching diode $D_{1}$, and an IGBT transistor $S W_{1}$. Through a skillful manipulation of the duty cycle $D$ in the buck converter, an MPP is tracked and the PV module array serves as a battery charger. The output voltage of a voltage divider formed from the resistors $R_{3}$ and $R_{4}$ and the current sensed by a current sensor are fed into a microcontroller, and then the battery output voltage $V_{B}$ and current $i_{B}$ are evaluated through the built-in ADCs. According to the detected voltage, the battery charger is operated in the preset mode.

When the charge current falls below a specified level owing to an insufficient supply of solar radiation, the MPP tracker is enabled for efficiency improvement. As the first step, a fraction of the PV module output voltage is fed into the microcontroller through a voltage divider consisting of the resistors $R_{1}$ and $R_{2}$, and then the PV module output voltage is found by means of a built-in ADC. Subsequently, an MPP tracking task is performed by regulating the PV module output voltage at the specified maximum power voltage on condition that the battery voltage lies below $58 \mathrm{~V}$, as illustrated in Fig. 6. 


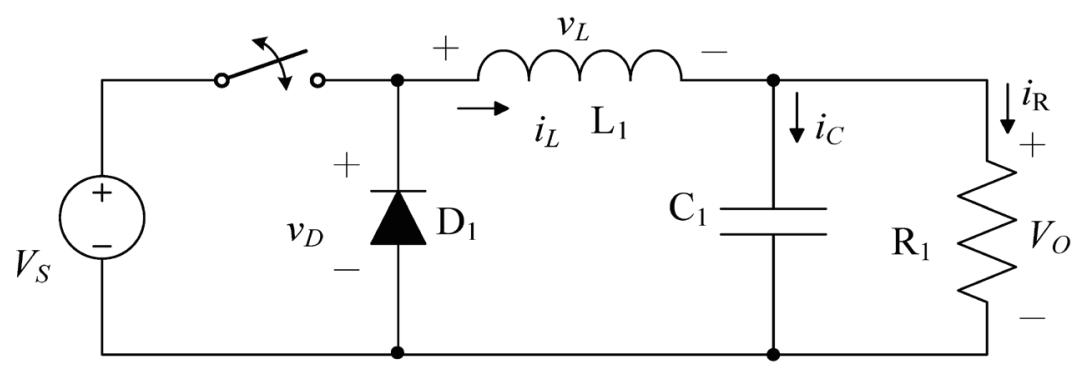

Fig. 4. Framework of a buck converter.

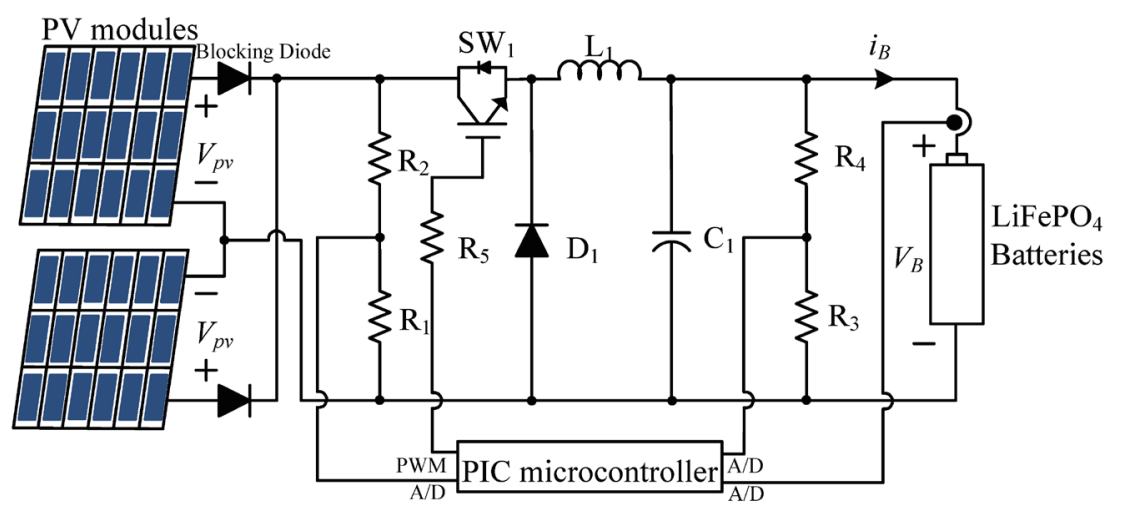

Fig. 5. (Color online) Framework of the presented battery charger controller.

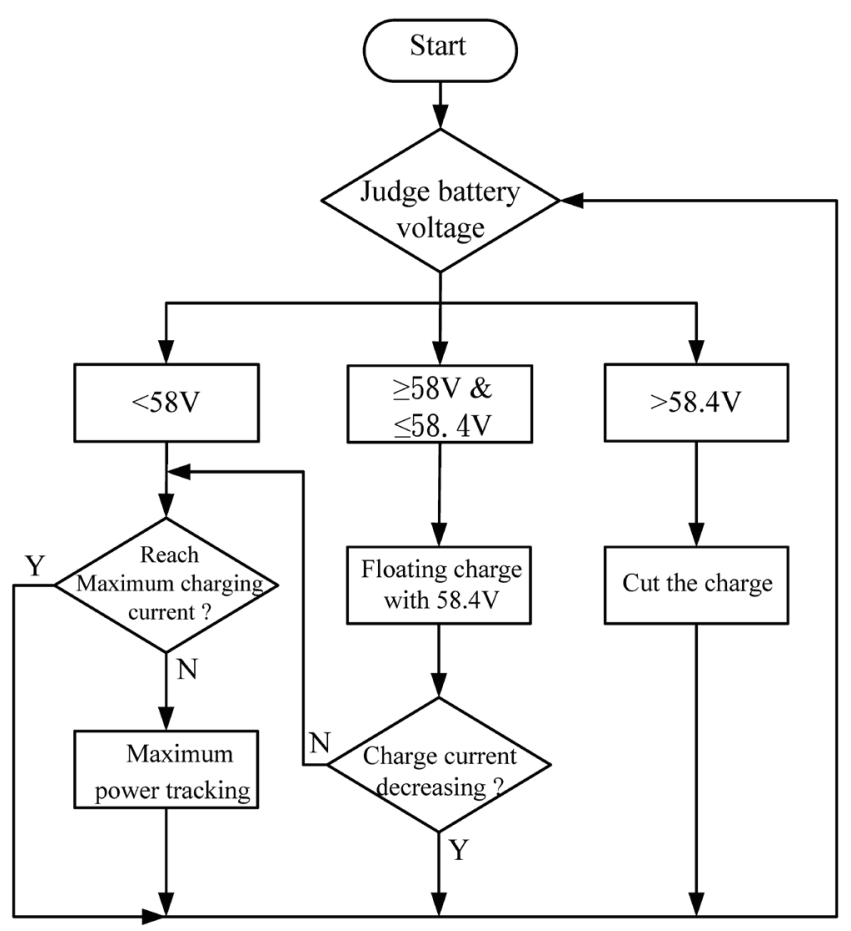

Fig. 6. Control flow chart of the presented battery charger. 


\section{3 $\quad \mathrm{LiFePO}_{4}$ battery charger design}

\subsubsection{PV module specifications}

Table 2 gives the electric specifications of a Kyocera KC40T PV module, ${ }^{(13)}$ according to which the presented battery charger is designed. As shown in Table 2, a Kyocera KC40T PV module provides an MPP output current of approximately $2.48 \mathrm{~A}$. Hence, as many as $12 \mathrm{PV}$ modules are cascaded as a high-speed battery charger to deliver a maximum output power of approximately $516 \mathrm{~W}$ toward an EA-480100-C15 $\mathrm{LiFePO}_{4}$ battery.

The battery charger is designed to operate only when the output voltage $V_{P V}$ of the PV module array lies between 62 and $208 \mathrm{~V}$ with a maximum charge current $i_{B}$ of $10 \mathrm{~A}$. The charging continues when the battery output voltage $V_{B}$ lies beyond $58 \mathrm{~V}$ and below $58.4 \mathrm{~V}$. According to Eq. (2), the duty cycle $D$ of the buck converter, illustrated in Fig. 5, is bounded by

$$
D_{\min }(=0.21) \leq D \leq D_{\max }(=0.95)
$$

and the load resistance $R_{L}$ is given as

$$
R_{L}=\frac{V_{B}}{i_{B}}=\frac{58.4}{10}=5.84(\Omega) .
$$

\subsubsection{Component choices}

Shown in Table 3 are the component choices for the proposed Li-iron battery charger. ${ }^{(12)}$

\subsection{Measurements}

Presented in Fig. 7 is a photograph of the implemented charge controller, programmed in C language, with a PIC18F8720 chip as the core. In consideration of measurement efficiency improvement, a PVS0120 PV simulator ${ }^{(14)}$ is employed to simulate the performance of an array of Kyocera KC40T PV modules, as specified in Table 2, and to conduct an MPPT performance test at various irradiation levels. The simulated PV module array offers an output voltage of $208 \mathrm{~V}$, an output current of $2.48 \mathrm{~A}$, and an output power of $516 \mathrm{~W}$, and the irradiation level is adjustable by a rotary knob.

Table 2

Electric specifications of KC40T PV module.

\begin{tabular}{lr}
\hline \multicolumn{2}{c}{ Type: KC40T } \\
\hline Maximum output power & $43 \mathrm{~W}$ \\
Current of maximum power point & $2.48 \mathrm{~A}$ \\
Voltage of maximum power point & $17.4 \mathrm{~V}$ \\
Open voltage & $21.7 \mathrm{~V}$ \\
Short current & $2.65 \mathrm{~A}$ \\
\hline
\end{tabular}

Table 3

Component choices for the employed buck converter.

\begin{tabular}{lc}
\hline Part & Specification and model \\
\hline Inductor & $120 \mu \mathrm{H} / \mathrm{AWG} 16 \#$ \\
Capacitor & $33 \mu \mathrm{F} / 100 \mathrm{~V}$ \\
Semiconductor switch & G4PH50UD/50 A, 1200 V \\
Diode & $40 \mathrm{EPF} 06 / 40 \mathrm{~A}, 600 \mathrm{~V}$ \\
\hline
\end{tabular}




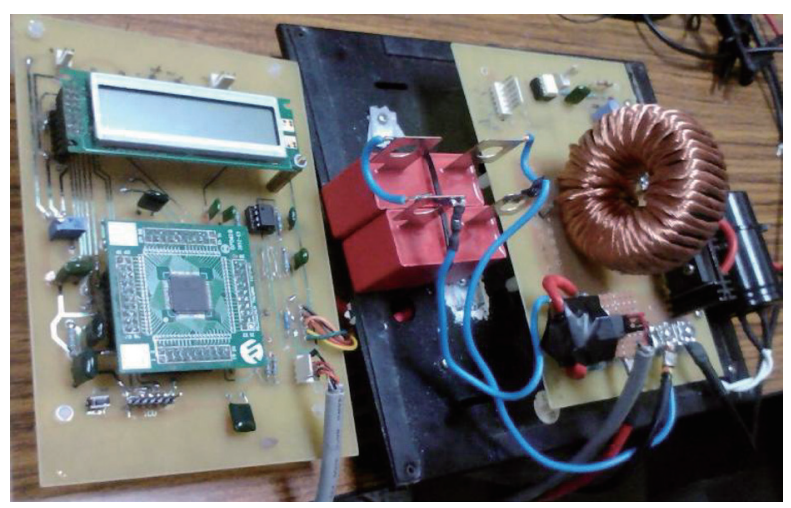

Fig. 7. (Color online) Photograph of the implemented battery charger.

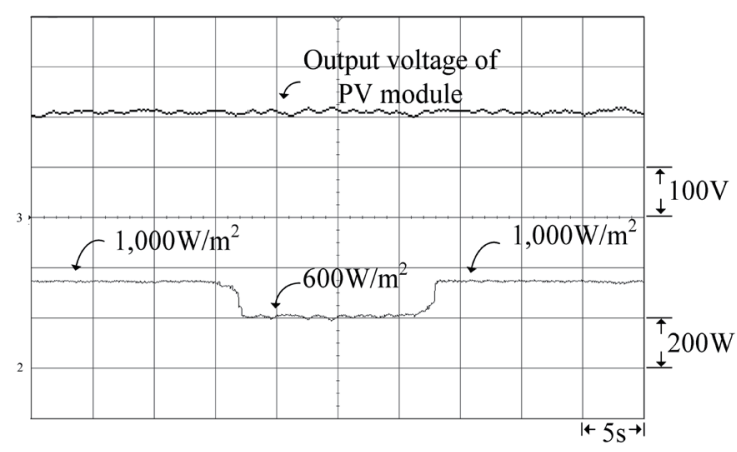

Fig. 8. Well-regulated output voltage of a PV module through a MPPT in response to an abrupt change in the level of incident solar radiation.

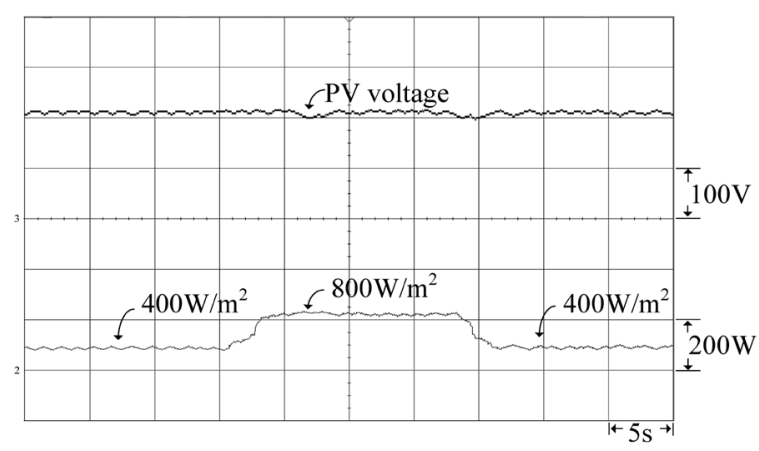

Fig. 9. The same experiment as in Fig. 8 is repeated except for a solar radiation change from 400 to 800 and then back to $400 \mathrm{~W} / \mathrm{m}^{2}$.

\subsubsection{Measured MPPT performance}

Presented in Fig. 8 is the measured performance of a constant-voltage MPPT approach in response to an abrupt drop in the level of solar radiation from 1000 to $600 \mathrm{~W} / \mathrm{m}^{2}$ at $t=15 \mathrm{~s}$ and then an abrupt rise back to $1000 \mathrm{~W} / \mathrm{m}^{2}$. There is evidence that the output voltage of the PV module array is well regulated at a specified level by the presented MPP tracker against abrupt irradiation changes.

The same experiment is repeated again for the MPPT performance test except that the irradiation level rises from 400 to $800 \mathrm{~W} / \mathrm{m}^{2}$ and then plunges to $400 \mathrm{~W} / \mathrm{m}^{2}$. As shown in Fig. 8, the output voltage of the PV module array in Fig. 9 is found to be well regulated again. 


\subsubsection{Measured battery charger performance}

Demonstrated in Fig. 10 are the measured PWM and charge current waveforms. In the presence of sufficient solar radiation, the charge current can be regulated at $10 \mathrm{~A}$ by the efficient manipulation of the PWM duty cycle via a PIC18F8720 chip.

As can be found in Fig. 11, the battery charger continues to operate in the constant current mode until a voltage threshold of $58 \mathrm{~V}$ is reached. Subsequently, the battery charger works in the constant voltage mode, during which a charge current drop of approximately $0.01 \mathrm{C}$ amps occurs.

\subsubsection{High-current charge/discharge characteristic}

For there is a nonuniform distribution of electrolyte in the interior of a Li-iron battery owing to redox reaction, particularly during a high current charge/discharge process, the battery cannot be measured until an equilibrium is reached. Illustrated in Fig. 12 is a flow chart for the

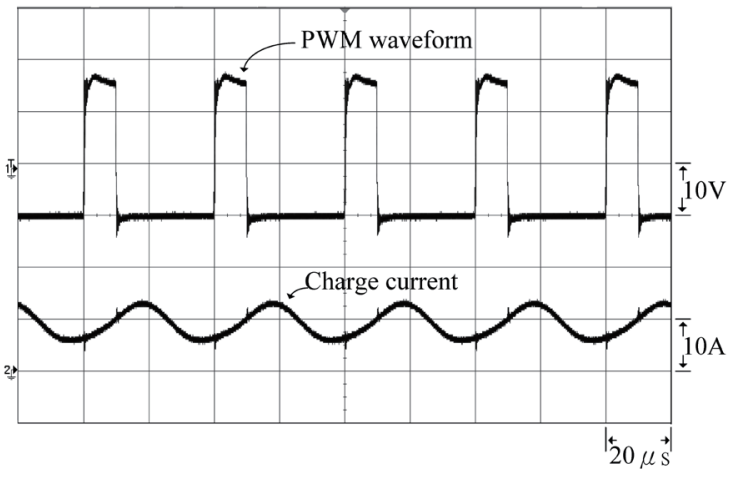

Fig. 10. Measured PWM and charge current waveforms in constant current mode.

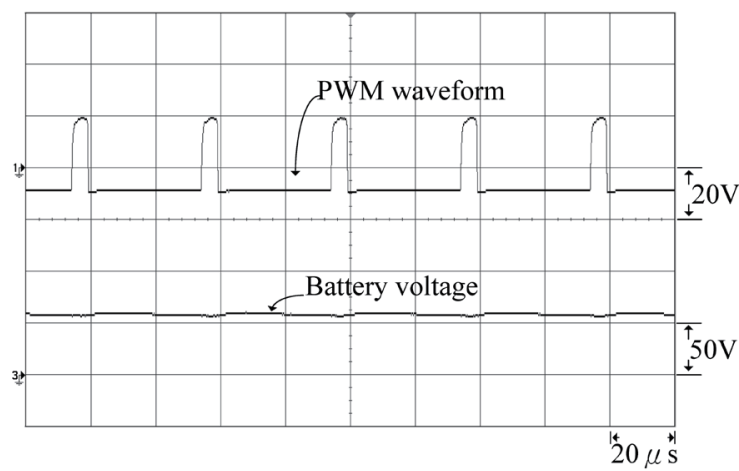

Fig. 11. Measured PWM and battery voltage waveforms in constant voltage mode.

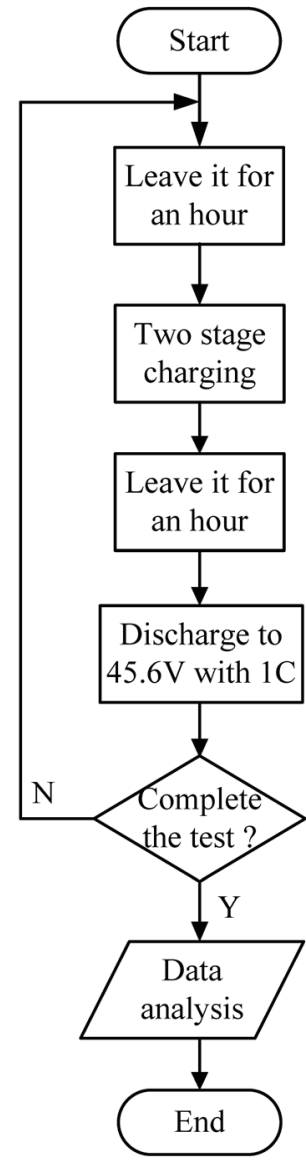

Fig. 12. Flow chart of a battery charge/discharge cycle. 
measurement of the battery charge/discharge characteristic curves. A fully discharged battery reaches a $0 \%$ SOC and then remains idle for $1 \mathrm{~h}$. A two-stage charging strategy is performed subsequently, that is, the battery is firstly charged at a constant current of $1 \mathrm{C}$ amp until the cutoff voltage is reached. The battery charger is then operated in the constant voltage mode until the charge current falls to $0.01 \mathrm{C}$ amps, a state treated as a $100 \%$ SOC. The battery remains idle for another hour, and then another battery discharge task is performed at a constant current of $1 \mathrm{C}$ amp. A TES-33 battery capacity tester, ${ }^{(15)}$ a product launched by TES Electric Electronic Corp., Taiwan, is adopted to plot graphs of the battery voltage, current, and SOC to understand battery behaviors over charge/discharge cycles.

Provided in Fig. 13 is a charging characteristic curve of an EA-480100-C15 Li-iron battery. It is found that the battery voltage rises rapidly at a constant charge current of $1 \mathrm{C}$ amp until a threshold of $53.29 \mathrm{~V}$ is reached, and then continues to increase linearly, but slowly, with time. In the constant current mode, the SOC rises linearly and rapidly with the battery voltage. At a $1 \mathrm{C}$ amp charge current, it takes as short as 45.7 min to reach an $80.2 \% \mathrm{SOC}$, and the charger operation is switched to the constant voltage mode once a voltage threshold of $58.4 \mathrm{~V}$ is reached. Furthermore, it takes 64.8 min to reach a $90.1 \%$ SOC. The charge current plunges once a cutoff voltage of $58.4 \mathrm{~V}$ is reached, and the battery charger is operated in the constant voltage mode. Hence, it is evident that the discharge timespan of an EA-480100-C15 Li-iron battery, as a solar energy storage device, can be reduced significantly.

Presented in Fig. 14 is a plot of battery temperature against time at a charge current of $1 \mathrm{C}$ amp for an EA-480100-C15 Li-iron battery. In the constant current mode, the temperature rises with time from 28.9 to $31.4{ }^{\circ} \mathrm{C}$ until a voltage threshold is reached. Subsequently, the charger operation is switched to the constant voltage mode, and the battery temperature and particularly the charge current start to fall instantly. A temperature rise lower than $3{ }^{\circ} \mathrm{C}$ is observed in the battery charge process in Fig. 14, eliminating the risk of overheating.

Provided in Fig. 15 is a measured discharge characteristic curve of an EA-480100-C15 Li-iron battery at a discharge current of $1 \mathrm{C}$ amp. As indicated in the figure, it takes the battery 59 min or so to reach the cutoff voltage together with a $4.4 \%$ SOC, a finding in good

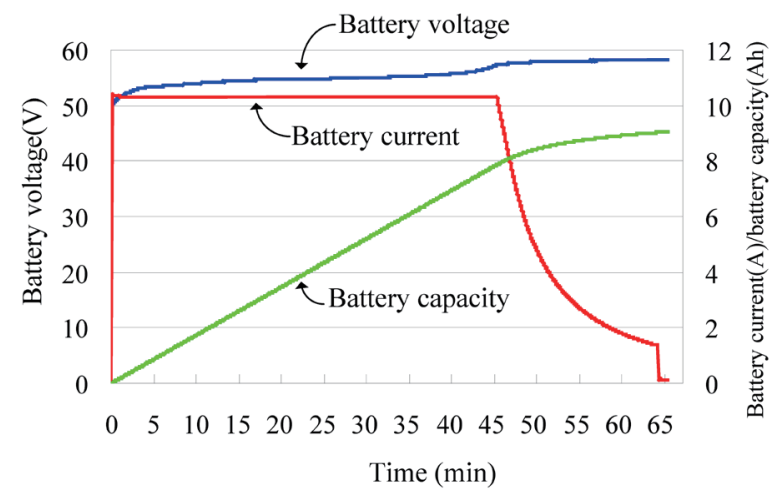

Fig. 13. (Color online) Two-stage charge characteristic curve for an EA-480100-C15 Li-iron battery at 1C amp in the constant current mode followed by the constant voltage mode. 


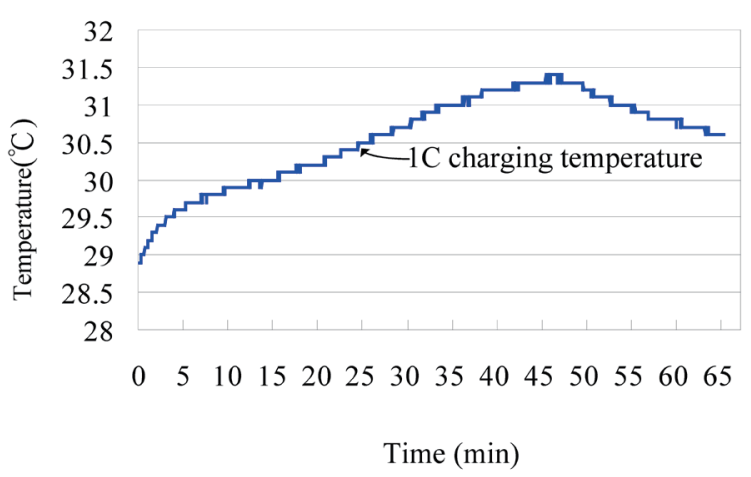

Fig. 14. (Color online) Plot of battery temperature versus time in the case in Fig. 13.

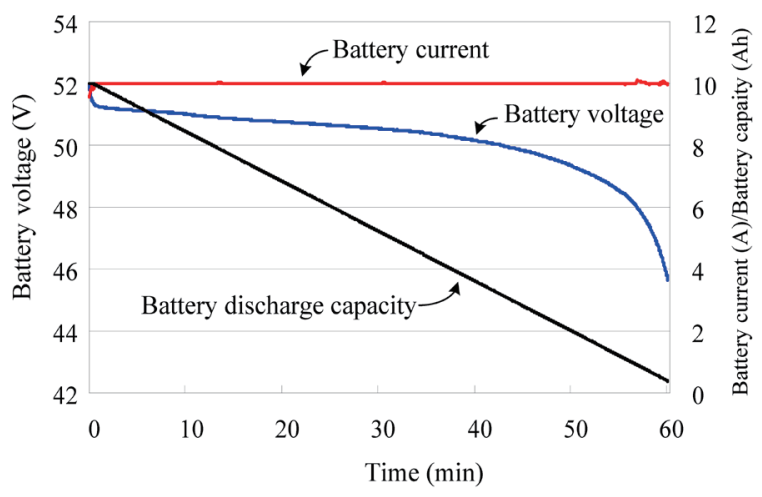

Fig. 15. (Color online) Discharge characteristic curve for an EA-480100-C15 Li-iron battery at 1C amp.

agreement with the specified $10 \mathrm{AH}$ battery capacity. The battery voltage decreases linearly with time from the initial 52.01 to $48.51 \mathrm{~V}$ together with an SOC of $11.86 \%$ over a timespan of approximately $55 \mathrm{~min}$. Subsequently, the battery voltage plunges to $45.63 \mathrm{~V}$, at which voltage, SOC is considered to be $0 \%$ herein. An average voltage of $48.82 \mathrm{~V}$ is observed over the entire discharge process, indicating the high performance of the Li-iron battery. If the energy conversion efficiency of the battery is defined as the ratio of "(average discharge voltage) * (average discharge capacity)" to "(average charge voltage) * (average charge capacity)", the measurement results show that the energy conversion efficiency of this energy storage system is $90 \%$. This energy conversion efficiency is much higher than those of other charge/discharge controllers.

\section{Conclusions}

In this paper, we presented an MPPT-based high-performance Li-iron battery charger, based on a buck converter and implemented on a PV system. A constant voltage approach is employed to perform an MPP tracking task. Moreover, a two-stage battery charging strategy is adopted in this work, i.e., charging operation in the constant current mode during the first stage of charging and then in the constant voltage mode during the second stage. Consequently, a $\mathrm{LiFePO}_{4}$ battery is charged rapidly at $1 \mathrm{C}$ amp, while an MPP tracker is enabled so as to deliver the maximum power to the battery in the event that the charge current falls below $1 \mathrm{C} \mathrm{amp.} \mathrm{In}$ contrast, the MPP tracker is disabled when the charge current is beyond $1 \mathrm{C}$ amp. The battery charger continues to operate in the constant current mode until a voltage threshold of $58 \mathrm{~V}$ is reached. At this point in time, the charger starts charging and then continues to operate in the constant voltage mode until another voltage threshold of $58.4 \mathrm{~V}$ is reached. In this manner, the presented two-stage high-performance strategy is validated as an effective approach not merely to speed up battery charging, but also to protect batteries from overcharging by temperature monitoring. It is worth mentioning that this high-performance charge/discharge controller uses only low-cost voltage, current, and temperature sensors. 


\section{References}

1 S. H. Yang and T. C. Tsai: Sci. Dev. 309 (2005) 50.

2 Y. J. Huang: Master of Thesis, National Changhua University of Education, Changhua, Taiwan (2006).

3 N. Karamia, N. Moubayedb, and R. Outbibc: Renewable Sustainable Energy Rev. 68 (2017) 1. https://doi. org/10.1016/j.rser.2016.09.132

4 O. Ezinwannea, F. Zhongwena, and L. Zhijunb: Energy Procedia 107 (2017) 297.

$5 \mathrm{http} / / / \mathrm{www} . \mathrm{microchip.com}$

6 "PIC18Fxx20 Data Sheet", Microchip Technology Inc. (2003). http://wwl.microchip.com/downloads/cn/ DeviceDoc/cn011897.pdf

7 T. Župa and O. Líška: IEEE 8th Int. Symp. Applied Machine Intelligence and Informatics (SAMI) (2010) 241-242. https://doi.org/10.1109/SAMI.2010.5423730

8 A. K. Padhi, K. S. Nanjundaswamy, and J. B Goodenough: J. Electrochem. 144 (1997) 1188. https://doi.org/ 10.1149/1.1837571

9 A. K. Padhi, K. S. Nanjundaswamy, C. Masquelier, S. Okada, and J. B. Goodenough: J. Electrochem. 144 (1997) 1609. https://doi.org/10.1149/1.1837649

10 C. Masquelier, A. K. Padhi, K. S. Nanjundaswamy, and J. B. Goodenough: Solid State Chem. 135 (1998) 228. https://doi.org/10.1006/jssc.1997.7629

11 D. I. Stroe, M. Swierczynski, A. I. Stroe, and S. K. Kær: Batteries 2 (2016) 1. https://doi.org/10.3390/ batteries 2040037

12 S. C. Wang: Power Electronic, Tung Hua Booj Co. Ltd. (2001) ISBN13: 9789576369131.

13 Kyocera Photovoltaic Module KC40T Specifications, Kyocera Solar Industries (May 2007).

14 PV Simulator-PVS0120 Specifications. http://www.kernel-sys.co.jp/product/PVsimulator.pdf

15 http://www.tes.com.tw/33c.htm

\section{About the Authors}

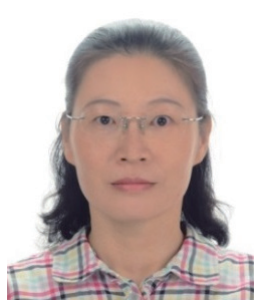

Pi-Yun Chen received her Ph.D. degree in engineering science and technology from National Yunlin University of Science and Technology, in 2011. Now she is an associate professor in the Department of Electrical Engineering, National Chin-Yi University of Technology, Taiwan. Her current research interests include fuzzy systems and advanced control systems.

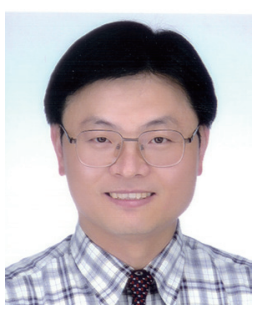

Kuei-Hsiang Chao received his B.S. degree in electrical engineering from National Taiwan Institute of Technology, Taipei, Taiwan, in 1988, and his M.S. and Ph.D. degrees in Electrical Engineering from National Tsing Hua University, Hsinchu, Taiwan, in 1990 and 2000, respectively. He is presently a professor at the National Chin-Yi University of Technology, Taichung, Taiwan. His areas of interest are computer-based control systems, applications of control theory, renewable energy, and power electronics. He is a life member of the Solar Energy and New Energy Association and a member of the IEEE.

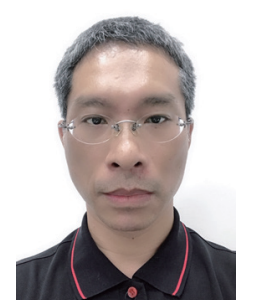

Yu-Sheng Tsai received his M.S. degree in electrical engineering from National Chin-Yi University of Technology in 2012. He is presently an engineer in Tranmax Machinery Co., Ltd. His research interests include photovoltaic power systems and energy storage systems. 